Li, Y., Shi, X., Emrouznejad, A., \& Liang, L. (2017). Environmental performance evaluation of Chinese industrial systems: a network SBM approach. Journal of the Operational Research Society, in press.

\title{
Environmental performance evaluation of Chinese industrial systems: A network SBM approach
}

\author{
Yongjun Li ${ }^{\mathrm{a}}$, Xiao Shi ${ }^{\mathrm{b} *}$, Ali Emrouznejad ${ }^{\mathrm{c}}$, Liang Liangd \\ ${ }^{\text {a }}$ School of Business, University of Science and Technology of China, Hefei, Anhui \\ Province, 230026, P.R. China, Email: lionli@mail.ustc.edu.cn \\ b School of Finance, Shandong University of Finance and Economics, Jinan, \\ Shandong Province, 250000, P.R. China, Email: shixiao@sdufe.edu.cn \\ c Aston Business School, Aston University, Birmingham, UK, Email:- \\ a.emrouznejad@aston.ac.uk \\ d School of Business, University of Science and Technology of China, Hefei, Anhui \\ Province, 230026, P.R. China, Email: $\underline{\text { lliang@ustc.edu.cn }}$
}

\begin{abstract}
In recent years, environmental problems caused by industries in China have drawn increasing attention to both academics and policy makers. This paper assesses the environmental efficiency of Chinese regional industrial systems to come up with some recommendations to policy makers. First, we divided each Chinese regional industrial system into a production process and a pollutant treatment process. Then, we built a scientific input-intermediate-output index system by introducing a new Network Slacks-Based Model (NSBM) model. This study is the first to combine NSBM with DEA window analysis to give a dynamic evaluation of the environmental efficiency. This enables us to assess the environmental efficiency of Chinese regional industrial systems considering their internal structure as well as China's policies concerning resource utilization and environmental protection. Hence, the overall
\end{abstract}


efficiency of each regional industrial system is decomposed into production efficiency and pollutant treatment efficiency.

Our empirical results suggest: (1) $66.7 \%$ of Chinese regional industrial systems are overall inefficient. $63.3 \%$ and of $66.7 \%$ Chinese regional industrial systems are inefficient in the production process and the pollutant treatment process, respectively. (2) The efficiency scores for the overall system and both processes are all larger in the eastern area of China than those of the central and western areas. (3) Correlation analysis indicates that $\mathrm{SO}_{2}$-generation intensity (SGI), solid waste-generation intensity (SWGI), COD-discharge intensity (CDI), and $\mathrm{SO}_{2}$-discharge intensity (SDI) have significantly negative impacts on the overall efficiency. (4) The overall inefficiency is mainly due to inefficiency of the pollutant treatment process for the majority of regional industrial systems. (5) In general, the overall efficiency was trending up from 2004 to 2010, indicating that the substantial efforts China has devoted to protecting the environment have yielded benefits.

Keywords: Data Envelopment Analysis (DEA); Network SBM model; Environmental performance; Window analysis; Chinese industrial systems

\section{Introduction}

Since the opening and reforms in 1978, China becomes a member of the whole world big market. Many developed countries have moved their polluting enterprises to China because of its weak environmental regulations and cheap labor force. China maintains a high rate in economic growth but also gets problems of environmental degradation, such as air protection, and $\mathrm{CO}_{2}$ emission reduction (Zhang and Wen, 2008). The major reason of environmental degradation is the huge pollutants from industries. Fortunately, in recent years the government and there peoples know the importance of environmental protection and climate change, and the government starts to develop a green economy to separate economic growth from the increasing emission of pollutions (Yang, 2012).

The Chinese government has made many environmental policies and taken much action toward resource conservation and environmental protection to control the 
industrial discharge of waste gas, waste water, and solid waste. The Environmental Protection Law was firstly enacted in 1979. Since then, China has established seven major laws concerning environmental protection ${ }^{1}$ (Chang and Wang, 2010). All of these laws can be employed to regulate emissions from various industries. To supplement these major laws, the Chinese central government has introduced many regulations, a range of environmental regulatory schemes (e.g. Environmental Impact Assessment (EIA), Three Synchronizations, and Pollution Levy System), and over 500 environmental standards to regulate industrial pollutions (Shi and Zhang, 2006). The government gradually constructs a resource-saving and ecologically-friendly society. However, China still faces the problems of the resource shortage and environmental pollution (Geng et al., 2007; Bian and Yang, 2010; Yang, 2012). With increasing concerns about resource usage and environmental issues, environmental performance evaluation has become more critical.

There has been a rapid increase in the number of studies using data envelopment analysis (DEA) to evaluate environmental performance (Zhou et al., 2008; Gomes and Lins, 2008). For example, several scholars evaluate the environmental performance of different regions and countries (Arcelus, Arocena, 2005; Sarkis, Cordeiro, 2009; Bremberger, Bremberger, Luptacik, Schmitt, 2014). The approaches of treating undesirable outputs in evaluating environmental performance can be classified into several groups (Liang et al., 2009; You and Yan, 2011). The first one treats the undesirable outputs directly as inputs (Berg et al., 1992; Hailu and Veeman, 2001) and applied in Bi et al. (2012) and Zhang and Choi (2013). The second group transforms undesirable outputs by adding a sufficiently large positive number to the undesirable output (Seiford and Zhu, 2002) and applied to measure the environmental efficiency of paper mills along the Huai River (Hua et al., 2007). The third introduces the concept of weak disposability in Färe et al. (1989), and applied in Bian and Yang (2010) and Zhou et al. (2007).

\footnotetext{
${ }^{1}$ These 7 major laws concerning environmental protection are: Environmental Protection Law; Law on Marine Environmental Protection; Law on Water Pollution Prevention and Control; Law on Air Pollution Prevention and Control; Law on Solid Waste Pollution Prevention and Control; Radioactive Pollution Prevention and Control Law; Environmental Noise Pollution and Prevention Law.
} 
All of these studies treated each DMU as a black box. In these previous studies on the environmental efficiency of Chinese industrial systems, the initial inputs are considered to produce the final outputs through this "black box" without considering the undesirable intermediates. This efficiency evaluation method may not be reasonable as it does not simulate the specific processes of the real Chinese regional industrial system. In reality, the Chinese regional industrial system can be divided into a production process and a pollutant treatment process. Pollutants generated in the production process are also inputs to the pollutant treatment process. In this case, when a regional industrial system is deemed as a "black box", we cannot identify how much inefficiency comes from the production process or how much from the pollutant treatment process. But when the internal process of the DMU is considered, the efficiency score of the DMU can be assessed accurately, and insights into the performance of the DMU can be obtained (Färe and Grosskopf, 2000).

In recent years, a number of studies have focused on Network DEA (NDEA) to consider the internal process of DMUs (Färe and Grosskopf, 2000; Lewis and Sexton, 2004; Tone and Tsutsui, 2009; Cook et al., 2010; Tone and Tsutsui, 2010; Kao, 2014). As results, NDEA has been extensively applied to many areas, such as hotels (Sexton and Lewis, 2003; Moreno and Lozano, 2014), R\&D departments (Liu and Lu, 2010), retail stores (Vaz et al., 2010), information technology (Chen and Zhu, 2004), insurance companies (Kao and Hwang, 2008), power-supply companies (You and Jie, 2014), incineration plants (Chen et al. 2012) and so on. NDEA has also been applied to dealing with undesirable variables though mostly undesirable outputs. Kordrostami and Amirteimoori (2005) firstly considered undesirable inputs and outputs in NDEA. Tone and Tsutsui (2010) extended the network SBM to the dynamic structure with undesirable intermediates. They considered the importance of inputs and desirable outputs separately. Lozano et al. (2013) proposed a Directional Distance Function (DDF) network DEA approach considering undesirable final outputs to assess the efficiency of airports. Lozano (2015) proposed a general networks slacks-based inefficiency (GNSBI) with undesirable final outputs to assess banks efficiencies. Khalili-Damghani and Shahmir (2015) proposed a network DEA model in the 
presence of uncertainty and undesirable final outputs to evaluate the efficiency of electrical networks. Recently, Liu et al. (2015) studied network DEA models, systematically, by considering undesirable inputs, intermediates, and outputs. They proposed that inconsistency may exist in deciding the desirability of intermediates ${ }^{2}$. They applied the proposed model to evaluate the efficiencies of China's listed banks. However, there is a lack of literature on applying NDEA to assess environmental performance of industrial systems in China by incorporating undesirable variables. Song et al. (2014) attempted to apply two independent DEA models to assess the environmental efficiencies of 36 Chinese coal enterprises. However, they treated the two-stage production system as two independent processes, which ignored the fact that the intermediates must be consistent both as the outputs of process one and inputs of process two.

All the previous studies on network DEA with undesirable variables have either separately considered the importance of inputs or desirable outputs or did not consider the importance of either. They neglected the importance of undesirable outputs. However, when undesirable outputs exist in each sub-system, we may overestimated the overall system as well as its sub-systems if the relative importance between inputs and undesirable outputs in sub-systems is ignored. Then, it may be unreasonable to estimate the environmental efficiency scores of the overall system and both sub-systems if each DMU has a preference on saving inputs and reducing undesirable outputs. However, none of prior studies in the network system with undesirable variables addressed this problem.

To approach the problem, we assign user-specific weights for inputs and undesirable outputs to reflect China's resource and environmental policy. In order to measure the dynamic changes in environmental performance and quantify their contributing factors, we also employ window analysis (Charnes and Cooper, 1984; Cooper et al., 2011) in our empirical study. This study makes two main contributions to the literature. First, this paper proposes a new Network SBM model that considers

\footnotetext{
${ }^{2}$ They pointed that inconsistence means that the types of intermediates from the system-view and sub-system view are different.
} 
the relative importance between inputs and undesirable outputs in both processes. It considers both the production process and pollutant treatment process in one network system to reflect the environmental performance of regional industrial systems in China for the first time. This study is the first to combine NSBM with DEA window analysis to give a dynamic evaluation of the environmental efficiency of regional industrial systems in China. Second, the study not only calculates and analyzes characteristics of different processes, which will give more accurate conclusions about environmental performance, but also provides insights on how to improve the efficiencies of the regional industrial systems in China. Therefore, this work offers important guidelines for policy implementation in the future development of Chinese regional industries.

The rest of this paper is as follows. In the next section, models for measuring each regional industrial system's overall efficiency, production efficiency, and pollutant treatment efficiency are presented. In Section 3, the empirical results of the Chinese regional industrial system from 2004 to 2010 are provided. Section 4 contains discussion of the results and in the last section, concluding remarks are given.

\section{Methodology}

In this study, the Chinese regional industrial system is divided into a production process and a pollutant treatment process. The network process of Chinese regional industrial system in this study is shown in Fig.1. Suppose in the production process, each regional industrial system $D M U_{j}(j=1, \ldots, n)$ has $m_{P}$ inputs $x_{i_{P} j}\left(i_{P}=1, \ldots, m_{P}\right)$, and uses these inputs to produce $s_{P}$ desirable outputs $y_{r_{P} j}\left(r_{p}=1, \ldots, s_{P}\right)$ as well as $D$ undesirable outputs $z_{d j}(d=1, \ldots, D)$. The $D$ undesirable intermediates $z_{d j}$ then become part of the inputs to the pollutant treatment process. The other part of the inputs are exogenous inputs $x_{i_{T} j}\left(i_{T}=1, \ldots, m_{T}\right)$. The outputs from the pollutant treatment process are desirable outputs $y_{r_{T} j}\left(r_{T}=1, \ldots, s_{T}\right)$ and undesirable outputs $u_{b j}(b=1, \ldots, B)$. The generated pollutants from the production process are referred to 
as the undesirable intermediates between the production process and the pollutant treatment process. Thus, the performance of the regional industrial system is determined by performance in both processes.

\section{<Insert Fig.1 here>}

Since each regional industry system's production process and pollutant treatment process are interdependent, it is better to jointly assess these two processes and estimate related performance indicators simultaneously. Thus, we propose a new Network SBM (NSBM) model with undesirable intermediates, undesirable outputs as well as user-specific weights for inputs and undesirable outputs in both processes. We define an overall network production possibility set in terms of $\left\{x_{i_{p}}\right\},\left\{z_{d}\right\},\left\{y_{r_{p}}\right\}$, $\left\{x_{i_{T}}\right\},\left\{y_{r_{T}}\right\}$, and $\left\{u_{b}\right\}$ as in the approach of Tone and Tsutsui (2010) and Liu et al. (2015) to get the following.

$$
\begin{aligned}
& T^{N}=\left\{x_{i_{P}}, z_{d}, y_{r_{P}}, x_{i_{T}}, y_{r_{T}}, u_{b}:\right. \\
& \sum_{j=1}^{n} \lambda_{j}^{P} x_{i_{P} j} \leq x_{i_{P}}, \quad \forall i_{P} \\
& \sum_{j=1}^{n} \lambda_{j}^{P} y_{r_{P} j} \geq y_{r_{P}}, \quad \forall r_{P} \\
& \sum_{j=1}^{n} \lambda_{j}^{P} z_{d j} \leq z_{d}, \quad \forall d \\
& \sum_{j=1}^{n} \lambda_{j}^{T} z_{d j} \leq z_{d}, \quad \forall d \\
& \sum_{j=1}^{n} \lambda_{j}^{T} x_{i_{T} j} \leq x_{i_{T}}, \quad \forall i_{T} \\
& \sum_{j=1}^{n} \lambda_{j}^{T} y_{r_{T} j} \geq y_{r_{T}}, \quad \forall r_{T} \\
& \sum_{j=1}^{n} \lambda_{j}^{T} u_{b j} \leq u u_{b}, \quad \forall b \\
& \left.\lambda_{j}^{P}, \lambda_{j}^{T} \geq 0, j=1, \ldots, n\right\}
\end{aligned}
$$

where $\lambda_{j}^{P}(j=1, \ldots, n)$ and $\lambda_{j}^{T}(j=1, \ldots, n)$ are the intensity variables for the production process and pollutant treatment process respectively. It is obvious the increase of intermediates $z_{d j}(d=1, \ldots, D)$ can produce more desirable outputs $y_{r_{T} j}$ 
$\left(r_{T}=1, \ldots, s_{T}\right)$ and undesirable outputs $u_{b j}(b=1, \ldots, B)$ in the pollutant treatment process. However, these intermediates are undesirable outputs of the production process. The intermediates $z_{d j}(d=1, \ldots, D)$ are desirable from the point view of the system but it is undesirable from a point of view of the production process. Thus, there exists inconsistence in deciding the desirability of the intermediates according to Liu et al. (2015). As the undesirable intermediates $z_{d j}$ serve as undesirable outputs of the production process and desirable inputs of the pollutant treatment process, we treat $z_{d j}$ as inputs to the production process similar to Liu et al. (2010) and Liu et al. (2015) (note constraint (1.3)), and also treat $z_{d j}$ as desirable inputs of the pollutant treatment process (note constraint (1.4)).

As the intermediates could be freely adjusted but should be consistent between the production process and pollutant treatment process ${ }^{3}$, the "free" intermediates between the production process and pollutant treatment process can be constrained by the condition below:

$$
\sum_{j=1}^{n} \lambda_{j}^{P} z_{d j}=\sum_{j=1}^{n} \lambda_{j}^{T} z_{d j}, \quad \forall d
$$

Under the current network production possibility set, the NSBM model of Fig.1 can be represented as follows:

\footnotetext{
${ }^{3}$ In our study, the undesirable intermediates refer to the pollutants generated from the production process and therefore they could be adjusted freely by industry production.
} 


$$
\begin{aligned}
& \min _{\theta^{N}, s_{i_{p}}^{+}, s_{d}^{+}, s_{r_{p}}^{+}, s_{i_{T}}^{+}, s_{T_{T}^{-}}, s_{b}^{+}, \lambda_{j}^{p}, \lambda_{j}^{T}} \theta_{k}^{N}\left(x_{i_{p}}, z_{d}, y_{r_{p}}, x_{i_{T}}, y_{r_{T}}, u_{b}\right) \\
& =\min \frac{w_{P}\left(1-\frac{\alpha_{1}}{m_{P}} \sum_{i_{P}=1}^{m_{P}} \frac{s_{i_{P}}^{+}}{x_{i_{p} k}}-\frac{\beta_{1}}{D} \sum_{d=1}^{D} \frac{s_{d}^{+}}{z_{d k}}\right)+w_{T}\left(1-\frac{\alpha_{2}}{m_{T}} \sum_{i_{T}=1}^{m_{T}} \frac{s_{i_{T}}^{+}}{x_{i_{T} k}}-\frac{\alpha_{2}}{\mathrm{D}} \sum_{d=1}^{D} \frac{s_{d}^{+}}{z_{d k}}-\frac{\beta_{2}}{B} \sum_{b=1}^{B} \frac{s_{b}^{+}}{u_{b k}}\right)}{w_{P}\left(1+\frac{1}{s_{P}} \sum_{r_{P}=1}^{s_{P}} \frac{s_{r_{P}}^{-}}{y_{r_{P} k}}\right)+w_{T}\left(1+\frac{1}{s_{T}} \sum_{r_{T}=1}^{s_{T}} \frac{s_{r_{T}}^{-}}{y_{r_{T} k}}\right)} \\
& \text { s.t. } \sum_{j=1}^{n} \lambda_{j}^{P} x_{i_{P} j}+s_{i_{P}}^{+}=x_{i_{p} k}, \quad \forall i_{P} \\
& \sum_{j=1}^{n} \lambda_{j}^{P} z_{d j}+s_{d}^{+}=z_{d k}, \quad \forall d \\
& \sum_{j=1}^{n} \lambda_{j}^{P} y_{r_{P} j}-s_{r_{P}}^{-}=y_{r_{P} k}, \quad \forall r_{P} \\
& \sum_{j=1}^{n} \lambda_{j}^{P} z_{d j}=\sum_{j=1}^{n} \lambda_{j}^{T} z_{d j}, \quad \forall d \\
& \sum_{j=1}^{n} \lambda_{j}^{T} z_{d j}+s_{d}^{++}=z_{d k}, \quad \forall d \\
& \sum_{j=1}^{n} \lambda_{j}^{T} x_{i_{T} j}+s_{i_{T}}^{+}=x_{i_{T} k}, \quad \forall i_{T} \\
& \sum_{j=1}^{n} \lambda_{j}^{T} y_{r_{T} j}-s_{r_{T}}^{-}=y_{r_{T} k}, \quad \forall r_{T} \\
& \sum_{j=1}^{n} \lambda_{j}^{T} u_{b j}+s_{b}^{+}=u_{b k}, \quad \forall b \\
& \lambda_{j}^{P}, \lambda_{j}^{T} \geq 0, \forall j \\
& s_{i_{P}}^{+}, s_{d}^{+}, s_{r_{P}}^{-}, s_{i_{T}}^{+}, s_{r_{T}}^{-}, s_{b}^{+} \geq 0, \quad \forall i_{P}, d, r_{P}, i_{T}, r_{T}, b
\end{aligned}
$$

It should be noted that (3.1) denotes the inputs of the first stage and (3.6) denotes the inputs of the second stage, In model (3), $s_{i_{P}}^{+}\left(i_{P}=1, \ldots, m_{P}\right), s_{d}^{+}(d=1, \ldots, D)$, and $s_{r_{P}}^{-}$ $\left(r_{P}=1, \ldots, s_{p}\right)$ are slack vectors corresponding to inputs, undesirable outputs, and desirable outputs in the production process, and $s_{d}^{++}(d=1, \ldots, D), s_{i_{T}}^{+}\left(i_{T}=1, \ldots, m_{T}\right)$, $s_{r_{T}}^{-}\left(r_{T}=1, \ldots, s_{T}\right)$, and $s_{b}^{+}(b=1, \ldots, B)$ are slack vectors corresponding to endogenous inputs, exogenous inputs, desirable outputs, and undesirable outputs in the pollutant treatment process. The subscript $k$ represents the DMU under evaluation. $\alpha_{1}$ and $\beta_{1}$ are user-specified weights for inputs and undesirable outputs in production process, hence, $\alpha_{1}+\beta_{1}=1 . \alpha_{2}$ and $\beta_{2}$ are the corresponding weights for the pollutant treatment process.

The objective function deals not only with input excess and output shortfall but 
also excess and shortfalls in the undesirable intermediates as main targets of evaluation in both processes. Thus, the objective is to account for all inefficiencies from inputs, desirable outputs, and undesirable outputs in both processes. The undesirable outputs should be reduced as much as possible while the desirable outputs should be increased. Thus, the slacks of undesirable outputs in the production process and pollutant treatment process are in the numerator being treated as inputs in our model, while the desirable outputs in the production process and pollutant treatment process are in the denominator.

If variable returns to scale (VRS) over the reference technology are assumed in the production process and pollutant treatment process, we impose $\sum_{j=1}^{n} \lambda_{j}^{P}=1$ and $\sum_{j=1}^{n} \lambda_{j}^{T}=1$ on the technology in model (3). Note that the $w_{P}$ and $w_{T}$ defined in this paper are intended to represent the relative importance or contribution of the efficiencies of the production process and pollutant treatment process, respectively ${ }^{4}$. They satisfy the condition $w_{P}+w_{T}=1$. The optimal objective value $\theta_{k}^{N^{*}}$ obtained in model (3) is the overall efficiency for $D M U_{k}$.

The NSBM model above is a fractional program model and difficult to solve. To solve the problem, model (3) can be transformed from a non-linear program to a linear program by using a Charnes-Cooper transformation as in the conventional SBM model by introducing a new variable $t(t>0)$ (Tone, 2001). Let

$$
t=\left\{w_{P}\left(1+\frac{1}{s_{P}} \sum_{r_{P}=1}^{s_{P}} \frac{s_{r_{P}}^{-}}{y_{r_{P} k}}\right)+w_{T}\left(1+\frac{1}{s_{T}} \sum_{r_{T}=1}^{s_{T}} \frac{s_{r_{T}}^{-}}{y_{r_{T} k}}\right)\right\}^{-1}
$$

Model (3) can be transformed to the following linear model (5) as

\footnotetext{
${ }^{4}$ In this paper, we simply set $w_{P}=w_{T}=0.5$ as the economic development and environmental protection are of equally importance in developing industries in China. 


$$
\begin{aligned}
& \min _{t, \hat{s}_{i}^{+}, \hat{s}_{d}^{+}, \hat{s}_{r_{p}}^{-}, \hat{s}_{i_{T}}^{+}, \hat{s}_{r_{T}^{-}}, \hat{s}_{b}^{,}, \hat{\lambda}_{j}^{p}, \hat{\lambda}_{j}^{T_{j}}} \tau_{k}^{N}\left(x_{i_{p}}, Z_{d_{p}}, y_{r_{p}}, X_{i_{T}}, y_{r_{T}}, u_{b}\right)= \\
& t-W_{P}\left(\frac{\alpha_{1}}{m_{P}} \sum_{i_{P}=1}^{m_{P}} \frac{\hat{s}_{i_{P}}^{+}}{X_{i_{P} k}}+\frac{\beta_{1}}{D} \sum_{d=1}^{D} \frac{\hat{s}_{d}^{+}}{Z_{d k}}\right)-W_{T}\left(\frac{\alpha_{2}}{m_{T}} \sum_{i_{T}=1}^{m_{T}} \frac{\hat{s}_{i_{T}}^{+}}{X_{i_{T} k}}+\frac{\alpha_{2}}{\mathrm{D}} \sum_{d=1}^{D} \frac{\hat{s}_{d}^{\prime}+}{Z_{d k}}+\frac{\beta_{2}}{B} \sum_{b=1}^{B} \frac{\hat{s}_{b}^{+}}{u_{b k}}\right) \\
& \text { s.t. } \quad \mathrm{t}+\frac{W_{P}}{m_{P}} \sum_{r_{P}=1}^{m_{P}} \frac{\hat{S}_{r_{P}}^{-}}{y_{r_{P} k}}+\frac{W_{T}}{m_{T}} \sum_{r_{T}=1}^{m_{T}} \frac{\hat{S}_{I_{T}}^{-}}{y_{r_{T} k}}=1 \\
& \sum_{j=1}^{n} \hat{\lambda}_{j}^{P} X_{i_{p} j}+\hat{s}_{i_{P}}^{+}=t x_{i_{p} k}, \quad \forall i_{P} \\
& \sum_{j=1}^{n} \hat{\lambda}_{j}^{P} Z_{d j}+\hat{S}_{d}^{+}=t z_{d k}, \quad \forall d \\
& \sum_{j=1}^{n} \hat{\lambda}_{j}^{P} y_{r_{P} j}-\hat{S}_{r_{p}}^{-}=t y_{r_{p} k}, \quad \forall r_{P} \\
& \sum_{j=1}^{n} \hat{\lambda}_{j}^{P} Z_{d j}=\sum_{j=1}^{n} \hat{\lambda}_{j}^{T} Z_{d j}, \quad \forall d \\
& \sum_{j=1}^{n} \hat{\lambda}_{j}^{T} z_{d j}+\hat{s}_{d}^{+}=t z_{d k}, \quad \forall d \\
& \sum_{j=1}^{n} \hat{\lambda}_{j}^{T} X_{i_{T} j}+\hat{S}_{i_{T}}^{+}=t x_{i_{T} k}, \quad \forall i_{T} \\
& \sum_{j=1}^{n} \hat{\lambda}_{j}^{T} y_{T_{T} j}-\hat{s}_{T_{T}}^{-}=t y_{T_{T} k}, \quad \forall r_{T} \\
& \sum_{j=1}^{n} \hat{\lambda}_{j}^{T} u_{b j}+\hat{s}_{b}^{+}=t u_{b k}, \quad \forall b \\
& \lambda_{j}^{P}, \lambda_{j}^{T} \geq 0, \forall j \\
& s_{i_{P}}^{+}, s_{d}^{+}, s_{r_{P}}^{-}, s_{i_{T}}^{+}, s_{T_{T}}^{-}, s_{b}^{+} \geq 0, \quad \forall i_{P}, d, r_{P}, i_{T}, r_{T}, b
\end{aligned}
$$

where $\hat{\lambda}_{j}^{P}=t \lambda_{j}^{P}, \hat{\lambda}_{j}^{T}=t \lambda_{j}^{T}, \hat{s}_{i_{P}}^{+}=t s_{i_{P}}^{+}, \hat{s}_{r_{P}}^{-}=t s_{r_{P}}^{-}, \hat{s}_{i_{T}}^{+}=t s_{i_{T}}^{+}, \hat{s}_{d}^{+}=t s_{d}^{+}, \hat{s}_{d}^{++}=t s_{d}^{+}$, $\hat{s}_{r_{T}}^{-}=t s_{r_{T}}^{-}$, and $\hat{s}_{b}^{+}=t s_{b}^{+}$. Let an optimal solution of model (5) be $\left(t^{*}, \hat{s}_{i_{P}}^{+*}, \hat{s}_{d}^{+*}, \hat{s}_{r_{P}}^{-*}, \hat{s}_{i_{T}}^{+*}, \hat{s}_{d}^{1^{+*}}, \hat{s}_{r_{T}}^{-*}, \hat{s}_{b}^{+*}, \hat{\lambda}_{j}^{P^{*}}, \hat{\lambda}_{j}^{T^{*}}\right)$, then the optimal solution of model (3) can be obtained as:

$$
\begin{aligned}
& \theta_{k}^{N^{*}}=\tau_{k}^{N^{*}}, \quad \lambda_{j}^{P^{*}}=\hat{\lambda}_{j}^{P^{*}} / t^{*}, \quad \lambda_{j}^{T^{*}}=\hat{\lambda}_{j}^{T^{*}} / t^{*}, \quad s_{i_{P}}^{+^{*}}=\hat{s}_{i_{P}}^{+^{*}} / t^{*}, \quad s_{r_{P}}^{-*}=\hat{s}_{r_{P}}^{-*} / t^{*}, \quad s_{i_{T}}^{+^{*}}=\hat{s}_{i_{T}}^{+^{*}} / t^{*}, \\
& s_{d}^{+*}=\hat{s}_{d}^{+*} / t^{*}, s_{d}^{+^{*}}=\hat{s}_{d}^{+^{*}} / t^{*}, \quad s_{r_{T}}^{-^{*}}=\hat{s}_{r_{T}}^{-*} / t^{*}, s_{b}^{+^{*}}=\hat{s}_{b}^{+*} / t^{*} \text {. }
\end{aligned}
$$

Accordingly, by solving model (5), we can obtain the optimal values of the overall efficiency $\tau_{k}^{N^{*}}$, and its corresponding two measures: production efficiency measure and pollutant treatment efficiency measure. Here, $\theta_{k}^{N^{*}}=\tau_{k}^{N^{*}}$, where $\theta_{k}^{N^{*}}$ are the optimal values from model (3). 
Let

$$
\begin{aligned}
& \delta_{k}^{P}=t+\frac{1}{m_{P}} \sum_{r_{P}=1}^{s_{P}} \frac{\hat{s}_{r_{P}}^{-}}{y_{r_{P} k}} \\
& \delta_{k}^{T}=t+\frac{1}{m_{T}} \sum_{r_{T}=1}^{s_{T}} \frac{\hat{s}_{r_{T}}^{-}}{y_{r_{T} k}} \\
& \xi_{k}^{P}=t-\frac{\alpha_{1}}{m_{P}} \sum_{i_{P}=1}^{m_{P}} \frac{\hat{s}_{i_{P}}^{+}}{x_{i_{P} k}}-\frac{\beta_{1}}{D} \sum_{d=1}^{D_{P}} \frac{\hat{s}_{d}^{+}}{z_{d k}} \\
& \xi_{k}^{T}=t-\frac{\alpha_{2}}{m_{T}} \sum_{i_{T}=1}^{m_{T}} \frac{\hat{s}_{i_{T}}^{T+}}{x_{i_{T} k}}-\frac{\alpha_{2}}{\mathrm{D}} \sum_{d=1}^{D} \frac{\hat{s}_{d}^{+}}{z_{d k}}-\frac{\beta_{2}}{B} \sum_{b=1}^{B} \frac{\hat{s}_{b}^{+}}{u_{b k}}
\end{aligned}
$$

Then, the optimal values of the production efficiency measure and pollutant treatment efficiency measure in model (3) can be calculated by $\theta_{k}^{P^{*}}=\frac{\xi_{k}^{P^{*}} / t^{*}}{\delta_{k}^{P^{*}} / t^{*}}=\xi_{k}^{P^{*}} / \delta_{k}^{P^{*}}$ and $\theta_{k}^{T^{*}}=\frac{\xi_{k}^{T^{*}} / t^{*}}{\delta_{k}^{T^{*}} / t^{*}}=\xi_{k}^{T^{*}} / \delta_{k}^{T^{*}}$, respectively.

The following definitions provide a measure of the overall efficiency and its decompositions:

Definition 1. (Overall efficiency, OE). The overall efficiency of $D M U_{k}$ is defined to be $\theta_{k}^{N^{*}}$, the optimal objective function value of model (3). $D M U_{k}$ is deemed to be overall efficient if and only if $\theta_{k}^{N^{*}}=1$ and all the slacks satisfy $s_{i_{P}}^{+^{*}}=0, s_{d}^{+^{*}}=0$, $s_{r_{P}}^{-*}=0, s_{d}^{t^{+*}}=0, s_{i_{T}}^{+^{*}}=0, s_{r_{T}}^{-*}=0$, and $s_{b}^{+^{*}}=0$.

Definition 2. (Production efficiency, PE). The production efficiency of $D M U_{k}, \theta_{k}^{P^{*}}$, is defined based on model (3) as

$$
\theta_{k}^{P^{*}}=\frac{1-\frac{\alpha_{1}}{m_{P}} \sum_{i_{P}=1}^{m_{P}} \frac{s_{i_{P}}^{+^{*}}}{x_{i_{P} k}}-\frac{\beta_{1}}{D} \sum_{d=1}^{D} \frac{s_{d}^{+^{*}}}{z_{d k}}}{1+\frac{1}{s_{P}} \sum_{r_{P}=1}^{s_{P}} \frac{s_{r_{P}}^{-*}}{y_{r_{P} k}}}
$$

$D M U_{k}$ is deemed to be production-efficient if and only if $\theta_{k}^{P *}=1$ and the slacks satisfy $s_{i_{P}}^{+^{*}}=0, s_{d}^{+^{*}}=0$, and $s_{r_{p}}^{-*}=0$.

Definition 3. (Pollutant treatment efficiency, PTE). The pollutant treatment efficiency 
of $D M U_{k}, \theta_{k}^{T^{*}}$, is defined based on model (3) as

$$
\theta_{k}^{T^{*}}=\frac{1-\frac{\alpha_{2}}{m_{T}} \sum_{i_{T}=1}^{m_{T}} \frac{s_{i_{T}}^{+*}}{x_{i_{T} k}}-\frac{\alpha_{2}}{\mathrm{D}} \sum_{d=1}^{D} \frac{s_{d}^{+^{* *}}}{z_{d k}}-\frac{\beta_{2}}{B} \sum_{b=1}^{B} \frac{s_{b}^{+*}}{u_{b k}}}{1+\frac{1}{s_{T}} \sum_{r_{T}=1}^{s_{T}} \frac{s_{r_{T}}^{-*}}{y_{r_{T} k}}}
$$

$D M U_{k}$ is deemed to be pollutant treatment-efficient if and only if $\theta_{k}^{T^{*}}=1$ and the slacks satisfy $s_{d}^{+^{* *}}=0, s_{i_{T}}^{+^{*}}=0, s_{r_{T}}^{-*}=0$, and $s_{b}^{+*}=0$.

In the proposed model, preferences or the relative importance between the inputs and undesirable outputs are taken into consideration in both processes. When the preference is removed (i.e., these two kinds of variables are treated in the same manner), the objective function becomes the objective of the traditional Network SBM, and can be formulated as:

$$
\theta_{k}^{N^{* *}}=\min \frac{w_{P}\left[1-\frac{1}{\mathrm{~m}_{\mathrm{P}}+D}\left(\sum_{i_{P}=1}^{m_{P}} \frac{s_{i_{P}}^{+^{* *}}}{x_{p_{P} k}}+\sum_{d=1}^{D} \frac{s_{d}^{+*}}{z_{d k}}\right)\right]+w_{T}\left[1-\frac{1}{m_{T}+D+B}\left(\sum_{i_{T}=1}^{m_{T}} \frac{s_{i_{T}}^{+^{*}}}{x_{i_{T} k}}+\sum_{d=1}^{D} \frac{s_{d}^{\prime+*}}{z_{d k}}+\sum_{b=1}^{B} \frac{s_{b}^{+*}}{u_{b k}}\right)\right]}{w_{P}\left(1+\frac{1}{s_{P}} \sum_{r_{P}=1}^{s_{P}} \frac{s_{r_{P}}^{-*}}{y_{r_{P} k}}\right)+w_{T}\left(1+\frac{1}{s_{T}} \sum_{r_{T}=1}^{s_{T}=1} \frac{s_{r_{T}}^{-*}}{y_{r_{T} k}}\right)}
$$

The corresponding efficiency measures in the production process and pollutant treatment process are defined as

$$
\begin{gathered}
\theta_{k}^{P^{* *}}=\frac{1-\frac{1}{m_{\mathrm{P}}+D}\left(\sum_{i_{P}=1}^{m_{P}} \frac{s_{i_{P}}^{+^{*}}}{x_{i_{P} k}}+\sum_{d=1}^{D} \frac{s_{d}^{+^{*}}}{z_{d k}}\right)}{1+\frac{1}{s_{P}} \sum_{r_{P}=1}^{s_{P}} \frac{s_{r_{P}}^{-*}}{y_{r_{P} k}}} \\
\theta_{k}^{T^{* *}}=\frac{1-\frac{1}{m_{T}+D+B}\left(\sum_{i_{T}=1}^{m_{T}} \frac{s_{i_{T}}^{+^{*}}}{x_{i_{T} k}}+\sum_{d=1}^{D} \frac{s_{d}^{+^{* *}}}{z_{d k}}+\sum_{b=1}^{B} \frac{s_{b}^{+^{*}}}{u_{b k}}\right)}{1+\frac{1}{s_{T}} \sum_{r_{T}=1}^{s_{T}} \frac{s_{r_{T}}^{-*}}{y_{r_{T} k}}}
\end{gathered}
$$

We have the following theorem:

Theorem 1. $\theta_{k}^{N^{*}} \leq \theta_{k}^{N^{*}}, \theta_{k}^{P^{*}} \leq \theta_{k}^{P^{* *}}, \theta_{k}^{T^{*}} \leq \theta_{k}^{T^{* *}}$ 
It is obvious that the proposed overall efficiency measure explains all inefficiencies including undesirable outputs in both the production process and pollutant treatment process. The theorem reflects that if the preferences between inputs and undesirable outputs in each process are ignored, then the overall efficiency, production efficiency, and pollutant treatment efficiency would be overestimated. Thus, in this paper, we adopt the efficiency measures (11) and (12) which consider the preferences between inputs and undesirable outputs to evaluate the production efficiency and pollutant treatment efficiency, respectively.

\section{Empirical results}

\subsection{Environmental efficiency analysis of regional industrial systems in China}

From the perspective of China's development and political factors, its 31 regions including autonomous regions and municipalities are divided into three major areas: eastern area, central area, and western area (Daniel, 1990). Since the environmental statistics of Tibet are incomplete, it is excluded and only the other 30 regions are evaluated.

According to the internal structure of Chinese regional industrial system discussed in Section 2, the characteristics of the dataset are summarized in Table 1. The selection of inputs and outputs of the production process in this paper follows previous studies on the environmental performance of Chinese industrial systems which deem each DMU as a "black box" (e.g., Bian and Yang, 2010; Bi et al. 2015; Zhang and Choi, 2013). Thus, in the production process, we select the total amount of employees, fixed assets, and electricity used by industry as the inputs. Intuitively, gross domestic product (GDP) can reflect the production stage, so we select GDP of the secondary industry as the desirable output of the industry. $\mathrm{COD}, \mathrm{SO}_{2}$, and solid waste are harmful to human health, so we select generated $\mathrm{COD}, \mathrm{SO}_{2}$, and solid waste as the undesirable outputs. Also, the generated $\mathrm{COD}, \mathrm{SO}_{2}$, and solid waste are disposed of in the pollutant treatment process by using pollutant treatment facilities. Thus, in the pollutant treatment process, we select these generated pollutants as re-input indicators and pollutant treatment investment in these facilities as an exogenous input. The value of comprehensive utilization of the three wastes (VCU) is 
chosen as an desirable output, and the emitted $\mathrm{COD}, \mathrm{SO}_{2}$, and solid waste are chosen as undesirable outputs. The data set in Table 1 was obtained from the China Statistical Yearbook 2011 published by the Chinese National Bureau of Statistics in 2011.

Table 1 shows that the data varies greatly from area to area. For example, the amount of COD emission ranges from 2.817 to 138.287 , and the standard deviation is 36.129. Thus, the effect of scale on the environmental efficiency score should be considered. The VRS assumption should be imposed on the model.

\section{<Insert Table 1 here $>$}

The empirical result of the modified NSBM model (5) is computed by program code in the Matlab language. However, when solving model (5), we have to appropriately set not only the parameters $\alpha_{1}$ and $\beta_{1}$ in the production process, but also the parameters $\alpha_{2}$ and $\beta_{2}$ in the pollutant treatment process. China has a goal to build a resource-saving and eco-friendly society. To achieve this goal, China implemented national policies concerning resource conservation and environmental protection, and these policies have played a vital role in changing the mode of development, protecting the environment, and regulating scientific progress. The Chinese government persists in laying equal emphasis on resource conservation and emission reduction, so based on the current conditions in China, resource saving and emission reduction are equally important, and we set $\alpha_{1}=\beta_{1}=0.5$ and $\alpha_{2}=\beta_{2}=0.5$. The results of model (5) are listed in Table 2.

\section{<Insert Table 2 here>}

Table 2 reports the results of the regional industrial systems' overall efficiency scores, production efficiency scores, pollutant treatment efficiency scores, and their ranks. Ten regions, namely Beijing (P1), Tianjin (P2), Shanghai (P5), Zhejiang (P7), Hainan (P10), Jilin (P14), Heilongjiang (P15), Jiangxi (P17), Inner Mongolia (P13), and Guizhou (P23), are overall efficient, production-efficient, and pollutant treatment-efficient, which means they rank first. It can be seen that any regional industrial system is efficient if and only if it is efficient in both processes. However, for each regional industrial system, an efficient production process does not guarantee 
an efficient pollutant treatment process, and vice versa. For example, Guangdong (P9) is efficient in the production process but not efficient in the pollutant treatment process.

Among the efficient regional industrial systems, five regions belong to the eastern area, four regions belong to the central area, and only one region belongs to the western area. This data indicates that the industry has achieved significant development in each of the three areas. To compare the differences between the three areas, consider the following. The average overall efficiency score of the eastern area at 0.781 is higher than the average overall score of the central and western areas at 0.748 and 0.58 , respectively. The average production efficiency score of the eastern area at 0.914 is higher than the average production efficiency score of the central and western areas at 0.889 and 0.756 , respectively. The average pollutant treatment efficiency score of the eastern area at 0.724 is higher than the average pollutant treatment efficiency score of the central and western areas at 0.691 and 0.570, respectively. Summarizing these differences, the regional industrial systems in the eastern area are more efficient than those in the central and western areas.

It is worth noting that inefficiency in two sub-processes reveals some of the hidden inefficiencies of the whole system. Kao and Huang (2008) identified the main causes of inefficiency of the whole two-stage system by identifying the sub-process with lower efficiency. We follow their method to identify the sub-process that mainly contributes to the overall inefficiency. Directions for improving the overall efficiency of each regional industrial system in the entire two-stage network process can also be identified. An efficiency $X-Y$ scatter diagram utilizing efficiencies of both processes is shown in Fig.2.

\section{<Insert Fig.2 here>}

In Fig.2, the horizontal and vertical axes of the efficiency diagram represent the production process efficiency and pollutant treatment process efficiency, respectively, and each regional industrial system is shown in the matrix. From this figure, we can see that the distribution of each regional industrial system is flat on the coordinate 
plane. A ray is drawn along the $45^{\circ}$ angle of coordinate axis to divide the entire coordinate plane into two parts. According to the location of the regional industrial system in the two parts, policy and strategic implications for improving overall performance can be proposed.

Sixteen regions - Hebei (P3), Liaoning (P4), Jiangsu (P6), Fujian (P8), Guangdong (P9), Shandong (P11), Anhui (P16), Henan (P18), Hubei (P19), Hunan (P20), Guangxi (P21), Sichuan (P22), Shaanxi (P25), Ningxia (P28) and Xinjiang (P29), and Chongqing (P30) - have higher production efficiency scores but lower pollutant treatment efficiency scores, as they are below the ray. This indicates that the low overall efficiencies of these regional industrial systems are mainly due to their low efficiency scores of the pollutant treatment process. Thus, these sixteen regions should pay more attention to the pollutant treatment process when pursuing economic increase. This is especially important for five regions -Sichuan (P22), Shaanxi (P25), Ningxia (P28), Xinjiang (P29), and Chongqing (P30) - since they are located in the western area where the ecological environment is very weak, making pollutant treatment there more important as industry develops. The regions located above the ray have higher pollutant treatment efficiencies but lower production efficiencies, including Shanxi (P12), Yunnan (P24), Gansu (P26) and Qinghai (P27). This indicates that the low overall efficiencies of these regional industrial systems are mainly due to their low efficiency scores of the production process, and thus these regions should pay more attention to that process. All of these regions, both above and below the ray, will be overall efficient if they reduce inputs and pollutants, and increase the desirable outputs, following the guidance of formula (6).

\section{<Insert Table 3 here>}

To investigate the impact of pollution on a region or country's overall efficiency, some previous literature on environmental efficiency used carbon intensity to monitor the region or country's environmental performance in $\mathrm{CO}_{2}$ emission(Lozano and Gutierrez, 2008; Bian and Yang, 2010). We follow this previous method by defining the following indicators in the production process and pollutant treatment process: 
electricity intensity (EI) as electricity-consumption per GDP, COD-generation intensity (CGI) as COD-generation per GDP, $\mathrm{SO}_{2}$-generation intensity (SGI) as $\mathrm{SO}_{2}$-generation/GDP ratio, solid waste-generation intensity (SWGI) as solid waste-generation per GDP, COD-discharge intensity (CDI) as COD-discharge per VCU, $\mathrm{SO}_{2}$-discharge intensity (SDI) as $\mathrm{SO}_{2}$-discharge per $\mathrm{VCU}$, and solid waste-discharge intensity (SWDI) as solid waste-discharge per VCU.

To investigate the impact of these pollutants on the overall efficiency, we calculate the correlations between overall efficiencies and all intensity variables. The results of using Spearman's correlation test are reported in Table 3. It can be observed that SGI, SWGI, CDI, and SDI have higher negative correlation with the overall efficiency (Spearman's correlation coefficients are $-0.367,-0.481,-0.643,-0.403$ ), while the EI, CGI, SWDI have lower negative correlation with the overall efficiency (Spearman's correlation coefficients are $-0.229,-0.312,-0.330$ ). These figures indicate that SGI, SWGI, CDI, and SDI have greater impacts on the overall efficiency than EI, CGI, and SWDI have. Therefore, to improve the overall efficiency, the government should pay more attention to controlling the generation of SO2 and solid waste in the production process, and the discharge of $\mathrm{COD}$ and $\mathrm{SO} 2$ in the pollutant treatment process.

\section{<Insert Table 4 here>}

Sensitivity analysis should be performed for different combinations of parameters on inputs and desirable outputs since the preference between inputs and undesirable outputs may be different in reality. For example, different countries may have different energy and environmental policies, or the same country in different time periods may have different policies for resource saving and pollutant treatment. These above results are computed with parameters $\alpha_{1}=\beta_{1}=0.5$ and $\alpha_{2}=\beta_{2}=0.5$, that is, assuming each region lays equal emphasis on reducing the inputs and undesirable outputs.

We should further perform sensitivity analysis for the overall system's efficiency with different value combinations of parameters $\left(\alpha_{1}, \beta_{1}\right)$ and $\left(\alpha_{2}, \beta_{2}\right)$. Table 4 lists the 
overall efficiency scores of the regional industrial systems and the corresponding ranks based on different value combinations of parameters $\left(\alpha_{1}, \beta_{1}\right)$ and $\left(\alpha_{2}, \beta_{2}\right)$. We see that for eachefficient regional industrial system, the efficient status of the system is insensitive to the parameters $\alpha_{1}$ and $\beta_{1}$. Efficient regional industrial systems always rank first and their efficiency is robust to parameter changes. As for the inefficient regional industrial systems, their rankings also stayed relatively stable as parameters varied. The regional industrial system with the largest ranking difference is Gansu (P26), which has a large ranking difference of 3 when the parameters change. The regional industrial system with the second ranking difference is Guangdong (P9), which has a large ranking difference of 2 when the parameters change. Other regional industrial system' rankings are almost same when the parameters change. Therefore, the rankings of regional industrial systems are not sensitive to the parameters. Also, it can be found from Table 4 that the overall efficiency scores of the regional industrial systems generally increase when $\alpha_{1}$ and $\alpha_{2}$ increase. Because the parameters satisfy $\alpha_{1}+\beta_{1}=1$ and $\alpha_{2}+\beta_{2}=1$, the overall efficiency scores of the regional industrial systems generally increase when $\beta_{1}$ and $\beta_{2}$ decrease.

\subsection{Window analysis}

Since China promotes a strategy of sustainable development, the government has increased spending on environmental protection year by year, and has achieved significant results (Liu, 2008). To examine whether Chinese industry performs well after years of continuous effort, and whether specific environmental policies affect performance of Chinese industry, we apply window analysis (Charnes and Cooper, 1984; Cooper et al., 2011) to 30 Chinese regional industrial systems to identify changes in the overall efficiency scores.

In this study, we analyze 30 Chinese regional industrial systems and a time period of 7 years (2004-2010) of efficiencies, so $n=30$ and $T=7$. It is known that a window with three or four time periods tends to yield the best balance of stability and information about the efficiency measure (Charnes, 1994). Following Zhang et al. 
(2011) and Wang et al. (2013), we chose a narrow window with a width of three $(w=3)$ to get credible environmental efficiency results. Thus, each regional industrial system is represented as a different DMU for each of the three following analyses. The first three years, 2004-2006, are the first window. Then the window moves on a one-year period by dropping the original year and adding a new year. This procedure continues until the last window (containing the last three years 2008-2010) is constructed. Doing this, we obtain five windows, and each window analysis consists of $90(n * w=30 * 3=90)$ scores.

\section{<Insert Table 5 here $>$}

The window analysis is applied based on model (5), and Hunan (P20) is taken as an example in Table 5, in which the calculation of the overall efficiency is shown. From the column data of Table 5, we can test the stability of the efficiency scores for each region across the different datasets. We find that the efficiency scores of all regions do not change significantly from the column view. This indicates that the results are stable across different datasets that occur with the moving of the window. Also, the row data enables us to examine the trends across the same dataset. According to the last row of Table 5, we find that the overall efficiency of Hunan (P20) had a slight decline from 2004 to 2005 whereas the efficiency increased from 2005 to 2010. We omitted the calculations for other 29 regions as the calculation procedures are similar. The results of the window analysis in the form of the overall efficiency of 30 regional industrial systems are shown in Tables 6. This tables shows the overall efficiency results of 30 such systems in China, grouped into three different areas and the whole country, in the study period from 2004 to 2010.

\section{<Insert Table 6 here $>$}

To examine whether specific environmental policies or regulations of the Chinese government affect the overall efficiency, we explore the changes in the overall efficiency scores before and after a certain policy or regulation is launched. It can be found in Table 6 that the overall efficiencies of eastern, central, and western areas as well as the whole country in 2007 are all higher than those in 2005 . China's 
Renewable Energy Law and Law on Promoting the Circular Economy were issued in 2005, both becoming effective in 2006, which may account for the increase of the overall efficiency in the three areas and the whole country in 2007. Additionally, the overall efficiencies of three areas and the whole country in 2008 are all higher than those in 2006. The National Development and Reform Commission (NDRC) released "Medium and Long Term Plan for Renewable Energy Development" in 2007, with the intention of reaching an ambitious target of renewable energy accounting for about $10 \%$ of the total energy consumption by 2010 and about $15 \%$ by 2020 .This policy of intending to increase use of clean energy may explain the rise of the overall efficiencies of the three areas and the whole country in 2008. Furthermore, the overall efficiencies of the three areas and the whole country in 2010 are all higher than those in 2008. In 2009, the state council passed a plan entitled "Environmental Impact Assessment Ordinance," which focuses on using the evaluation management method to prevent environmental pollution. This may be the reason the overall efficiencies of the three areas and the whole country increased in 2010.Thus, effective policies or regulations of resource and environment have positive effects on the improvement of overall efficiency.

It can be observed in Table 6 that the overall efficiency scores of the eastern area, central area, western area, and whole country increased during the study period 2004 to 2010 with the average overall efficiency score improving by $30.73 \%, 31.48 \%$, $14.25 \%$, and $28.72 \%$, respectively. This finding that the overall efficiency was trending up from 2004 to 2010 indicates that the substantial efforts spent on protecting the environment have yielded benefits nationwide.

\section{Discussion}

Our results provide environmental efficiency analysis of regional industrial systems in China by proposing a new Network SBM model which considers China's policies on resource utilization and environmental protection. As shown in Table 2, only 10 regional industrial systems were overall efficient, and most regional industrial systems were still at a low level of environmental efficiency in 2010. Thus, there is considerable room for improvement in Chinese industry. Because local governments 
pursue GDP growth, they ignore environmental degradation and poor resource utilization. Such a governance framework has encouraged low eco-efficiency activities and neglected proper disposal of pollutants, thus causing crises in both resource shortage and environmental risks. Our results, particularly the analysis using formula (6), could provide advice for local governments to improve environmental efficiencies in their sphere of influence.

The average overall efficiency scores, average production efficiency scores, and average pollutant treatment scores of the eastern area are all higher than those of the central and western areas. In China, the eastern region is the center of the economy and politics. Many relatively developed regions are located in the eastern area, which usually has more modern industries, advanced technology, higher management levels, and high-quality human resources. These advantages undoubtedly aid in using resources more efficiently and discharging fewer pollutants (Zhang et al., 2008). Furthermore, it is well known that the eastern region has a high level of regulation for industrial pollution and other environmental problems, regulated by not only the Chinese national government but also the local governments. As a result of technological advancement and governmental regulation, the eastern area has high overall efficiency scores, production efficiency scores, and pollutant treatment scores.

Note that in Table 2 and Fig. 2, the overall inefficiency of Shanxi (P12), Yunnan (P24), Gansu (P26), and Qinghai (P27) ismainly due to the inefficiency of the production process. The pillar industries of Shanxi (P12) are coal, coking, metallurgy and electric power production. These industries consume many resources and produce severe pollutants. Yunnan (P24), Gansu (P26), and Qinghai (P27) are all located in the western area that is the least developed area in China, with a relatively lagging industrial sector. Therefore, these regions have low production efficiency.

In general, the overall efficiency was trending up during the period 2004 to 2010, indicating that both national economic development and pollution control have made significant progress during the study period. Thus, the substantial efforts spent on protecting the environment have yielded benefits.

The empirical results can serve as a practical tool for policy-makers to make 
policies on resource saving and environmental protection in Chinese regional industry. The main policy implications of the research can be summarized as follows:

First, the central government should encourage inter-regional technological cooperation. Thus, the undeveloped central and western regions should cooperate with the eastern region to learn and improve their technology. Encouraging the industrial transformation is also necessary, for example, making more effort in designing sustainable production, and launching the evaluation of sustainable design performance.

Second, the sixteen regional industrial systems whose overall inefficiency is mainly due to the inefficiency of the pollutant treatment process should pay more attention to pollutant treatment when pursuing economic increase. More efforts should be exerted to encourage the industrial enterprises to use the pollutant treatment facilities. For example, the government should punish the industry enterprises that abnormally use the pollutant treatment facilities (especially the pollutant treatment facilities for abating SO2 and COD). These industrial enterprises must be fined and given warnings to use the pollutant treatment facilities consistently. The industrial enterprises should be ordered to pay attention to the inspection and maintenance of the pollutant treatment facilities. The four regional industrial systems whose overall inefficiency is mainly due to the inefficiency of the production process should pay more attention to improving production efficiency. It is advisable for the government to encourage the industrial enterprises to invest in developing improved technologies to improve resource and energy utilization efficiency. Since it is beneficial to use the financing instruments such as banking loans to achieve this goal, the government should encourage banks to provide low-interest and special loans for pollutant abatement to enterprises to support updating production technology and implementing clean production.

Third, the government should carry out training activities about environmental laws, regulations, and policy to industrial enterprises to make them realize the significant effect of the environmental protection on the enterprise's own development. Strengthening the environmental consciousness of industrial enterprises can 
encourage them to carry out effective measures of environmental protection consciously and actively. For example, the government should train the accountants of industrial enterprises to have a comprehensive knowledge of the costs and benefits of environmental practices, sustainable development, and so on. It is also necessary for the government to supervise the environmental assessment and promote the disclosure of environmental accounting information for each enterprise.

Fourth, the government should continue to refine policies related to environmental protection and apply them to industry. On the one hand, the government should speed up developing norms and standards for pollutant discharge calculation and control, cleaner production auditing, environmental engineering construction management, and so on. On the other hand, the government should promptly formulate supporting regulations to ensure effective enforcement of laws. For example, to change any situation where the cost of illegal action is low and the cost of compliance is high, the government should enforce regulations requiring fines that increase significantly for each day of infraction, with no upper limit. For example, the fine could rise by $20 \%$ for each day of illegal pollution by the enterprise, including starting at the previous penalty level the next time the pollution occurs.

\section{Conclusions}

In this paper, we propose a new Network SBM (NSBM) model to assess the environmental efficiencies of Chinese regional industrial systems under a serial network structure. Compared to the previous literature on environmental performance, the model considers the inner structure of the regional industrial systems in China and is based on a non-radial approach. Moreover, the model includes user-specific weights for inputs and undesirable outputs to reflect China's resource and environmental policies. The NSBM model proposed in the paper obtains the overall efficiency as well as production efficiency and pollutant treatment efficiency by maximizing the slacks of all the inputs, undesirable intermediates, and outputs in both the production process and the pollutant treatment process.

The empirical study indicates the following results. First, most Chinese regional industrial systems are not overall efficient, production-efficient, and pollutant 
treatment-efficient. Second, the average overall efficiency scores, average production efficiency scores, and average pollutant treatment scores of the eastern area are all larger than those of the central and western areas. Third, sixteen regional industrial systems' overall inefficiency is mainly due to the inefficiency of their pollutant treatment processes, while four regional industrial systems' overall inefficiency is mainly due to the inefficiency of their production processes. Fourth, the regression results indicate that $\mathrm{SO}_{2}$-generation intensity (SGI), solid waste-generation intensity (SWGI), COD-discharge intensity (CDI), and $\mathrm{SO}_{2}$-discharge intensity (SDI) have significant impacts on the overall efficiency. Fifth, the substantial efforts China has made to protect the environment have yielded benefits as the overall efficiency trended up during the period 2004 to 2010.Based on the empirical results, some practical suggestions are provided for policy-makers to regulate environmental protection in the industrial sector.

Finally, it should be noted that the results of the empirical study presented are dependent on the regions included, the choice of variables, and the data set used. Given data availability, this study could be expanded by using data from a longer or more recent time period. Unfortunately, the required data on pollution from Chinese regional industrial systems has not been made public since 2010. Further research may be done with more current data and longer time periods by using these methods with time series data.

\section{Acknowledgements}

The authors would especially like to thank Prof. Joe Zhu for his helpful comments and suggestions. This research is supported by the National Natural Science Foundation of China under Grants (No. 71271196 and No. 71671172), National Science Foundation of China for Distinguished Youth Scholars (No. 71225002), Science Funds for Creative Research Groups of University of Science and Technology of China (No. WK2040160008). 


\section{References}

Arcelus FJ, Arocena, P (2005). Productivity differences across OECD countries in the presence of environmental constraints. Journal of the Operational Research Society 56(12):1352-1362.

Berg SA, Forsund FR, Jansen ES (1992). Malmquist indices of productivity growth during the deregulation of Norwegian banking, 1980-89. Scandinavian Journal of Economics 94: S211-228.

Bi G, Luo Y, Ding J, Liang L (2015). Environmental performance analysis of Chinese industry from a slacks-based perspective. Annals of Operations Research 228: 65-80.

Bian Y, Yang F (2010). Resource and environment efficiency analysis of provinces in China: a DEA approach based on Shannon's entropy. Energy Policy 38:1909-1917.

Bremberger C, Bremberger F, Luptacik M, and Schmitt S (2015). Regulatory impact of environmental standards on the eco-efficiency of firms. Journal of the Operational Research Society 66(3): 421-433.

Chang YC, Wang N (2010). Environmental regulations and emissions trading in China. Energy Policy 38: 3356-3364.

Charnes A (1994). Data envelopment analysis: theory, methodology and applications. Springer.

Charnes A, Cooper WW (1984). Preface to topics in data envelopment analysis. Annals of Operations Research 2: 59-94.

Chen PC, Chang CC, Yu MM et al. (2012). Performance measurement for incineration plants using multi-activity network data envelopment analysis: The case of Taiwan. Journal of Environmental Management 93(1):95-103.

Chen Y, Zhu J (2004). Measuring information technology's indirect impact on firm performance. Information Technology and Management 5: 9-22.

Cook WD, Liang L, Zhu, J (2010). Measuring performance of two-stage network structures by DEA: a review and future perspective. Omega 38: 423-430.

Cooper WW, Seiford LM, Zhu J (2011). Data envelopment analysis: history, models, and interpretations. Handbook on data envelopment analysis. Springer, pp. 1-39.

Daniel WW, 1990. Applied nonparametric statistics.

Färe R, Grosskopf S (2000). Network DEA. Socio-economic planning sciences 34: 35-49.

Färe R, Grosskopf S, Lovell CK, Pasurka C (1989). Multilateral productivity comparisons when some outputs are undesirable: a nonparametric approach. The review of Economics and Statistics 71: 90-98.

Geng Y, Haight M, Zhu Q (2007). Empirical analysis of eco - industrial development in China. Sustainable Development 15:121-133.

Gomes EG, Lins ME (2008). Modelling undesirable outputs with zero sum gains data envelopment analysis models. Journal of the Operational Research Society 59(5): 616-623.

Hailu A, Veeman TS (2001). Non-parametric Productivity Analysis with Undesirable Outputs: An Application to the Canadian Pulp and Paper Industry. American Journal of Agricultural Economics 83: 605-616.

Hua Z, Bian Y, Liang L (2007). Eco-efficiency analysis of paper mills along the Huai River: an extended DEA approach. Omega 35: 578-587.

Kao C (2014). Network data envelopment analysis: A review. European Journal of Operational Research 239(1):1-16.

Kao C, Hwang SN (2008). Efficiency decomposition in two-stage data envelopment analysis: An 
application to non-life insurance companies in Taiwan. European Journal of Operational Research 185: 418-429.

Khalili-Damghani K, Shahmir Z (2015). Uncertain network data envelopment analysis with undesirable outputs to evaluate the efficiency of electricity power production and distribution processes. Computers \& Industrial Engineering 88:131-150.

Kordrostami S, Amirteimoori A (2005). Undesirable factors in multi-component performance measurement. Applied Mathematics \& Computation 171:721-729.

Lewis HF, Sexton TR (2004). Network DEA: efficiency analysis of organizations with complex internal structure. Computers \& Operations Research 31:1365-1410.

Liang L, Li Y, \& Li S (2009). Increasing the discriminatory power of DEA in the presence of the undesirable outputs and large dimensionality of data sets with PCA. Expert systems with applications 36(3):5895-5899.

Liu JS, Lu WM (2010). DEA and ranking with the network-based approach: a case of R\&D performance. Omega 38: 453-464.

Liu L (2008). Sustainability efforts in China: reflections on the environmental Kuznets curve through a locational evaluation of "Eco-Communities". Annals of the Association of American Geographers 98: 604-629.

Liu W, Meng W, Li X, Zhang D (2010). DEA models with undesirable inputs and outputs. Annals of Operations Research 173: 177-194.

Liu W, Zhou Z, Ma C, Liu D, Shen W (2015). Two-stage DEA models with undesirable input-intermediate-outputs. Omega 56,74-87.

Lozano S (2015). Slacks-based inefficiency approach for general networks with bad outputs: An application to the banking sector. Omega 60: 73-84

Lozano S, Gutiérrez E, Moreno P (2013). Network DEA approach to airports performance assessment considering undesirable outputs. Applied Mathematical Modelling 37:1665-1676.

Lozano S, Gutierrez E (2008). Non-parametric frontier approach to modelling the relationships among population, GDP, energy consumption and $\mathrm{CO} 2$ emissions. Ecological Economics 66: 687-699.

Moreno P, Lozano S (2014). A network DEA assessment of team efficiency in the NBA. Annals of Operations Research 214:99-124.

Sarkis J, Cordeiro JJ (2009). Investigating technical and ecological efficiencies in the electricity generation industry: are there win-win opportunities?. Journal of the Operational Research Society 60(9): 1160-1172.

Seiford LM, Zhu J (2002). Modeling undesirable factors in efficiency evaluation. European Journal of Operational Research 142:16-20.

Sexton TR, Lewis HF (2003). Two-stage DEA: An application to major league baseball. Journal of Productivity Analysis 19: 227-249.

Shi H, Zhang L (2006). China's environmental governance of rapid industrialisation. Environmental Politics 15: 271-292.

Song M, Wang S, Cen L (2014). Comprehensive efficiency evaluation of coal enterprises from production and pollution treatment process. Journal of cleaner production 104:374-379.

Tone K (2001). A slacks-based measure of efficiency in data envelopment analysis. European Journal of Operational Research 142: 16-20.

Tone K, Tsutsui M (2009). Network DEA: a slacks-based measure approach. European Journal of 
Operational Research 197: 243-252.

Tone K, Tsutsui M (2010). Dynamic DEA: a slacks-based measure approach. Omega 38:145-156.

Vaz CB, Camanho A, Guimarães R (2010). The assessment of retailing efficiency using network data envelopment analysis. Annals of Operations Research 173: 5-24.

Wang K, Yu S, Zhang W (2013). China's regional energy and environmental efficiency: a DEA window analysis based dynamic evaluation. Mathematical and Computer Modelling 58: 1117-1127.

Yang Z (2012). The Right to Carbon Emission: A New Right to Development. America Journal of Climate Change 1:108.

You S, Yan H (2011). A new approach in modelling undesirable output in DEA model. Journal of the Operational Research Society 62(12): 2146-2156.

You YQ, Jie T (2014). A study of the operation efficiency and cost performance indices of power-supply companies in china based on a dynamic network slacks-based measure model. Omega 60: 85-97.

Zhang B, Bi J, Fan Z, Yuan Z, Ge J (2008). Eco-efficiency analysis of industrial system in China: a data envelopment analysis approach. Ecological Economics 68: 306-316.

Zhang KM, Wen ZG (2008). Review and challenges of policies of environmental protection and sustainable development in China. Journal of Environmental Management 88: 1249-1261.

Zhang N, Choi Y (2013). Environmental energy efficiency of China's regional economies: A non-oriented slacks-based measure analysis. The Social Science Journal 50: 225-234.

Zhang XP, Cheng XM, Yuan JH, Gao XJ (2011). Total-factor energy efficiency in developing countries. Energy Policy 39:644-650.

Zhou P, Ang BW, Poh KL (2008). A survey of data envelopment analysis in energy and environmental studies. European Journal of Operational Research 189, 1-18.

Zhou P, Poh KL, Ang BW (2007). A non-radial DEA approach to measuring environmental performance. European Journal of Operational Research 178: 1-9. 


\section{Appendix A}

Theorem 1. $\theta_{k}^{N^{*}} \leq \theta_{k}^{N^{*}}, \theta_{k}^{P^{*}} \leq \theta_{k}^{P^{* *}}, \theta_{k}^{T^{*}} \leq \theta_{k}^{T^{* *}}$

Proof: The constraints of model (3) and model (13) are same, so we can just compare the objective.

Let $A=\sum_{i_{P}=1}^{m_{P}} \frac{x_{i_{P} k}-s_{i_{P}}^{+}}{x_{i_{P} k}} \leq m_{P}, E=\sum_{d=1}^{D} \frac{z_{d k}-s_{d}^{+}}{z_{d k}} \leq D, C=1+\frac{1}{m_{P}} \sum_{r_{P}=1}^{m_{P}} \frac{s_{r_{P}}^{-}}{y_{r_{P} k}}$,

$A^{\prime}=\sum_{i_{T}=1}^{m_{T}} \frac{x_{i_{T} k}-s_{i_{T}}^{+}}{x_{i_{T} k}} \leq m_{T} \quad, \quad E^{\prime}=\sum_{b=1}^{B} \frac{u_{b k}-s_{b}^{+}}{u_{b k}} \leq B \quad, \quad F=\sum_{d=1}^{D} \frac{z_{d k}-s_{d}^{\prime+}}{z_{d k}} \leq D \quad$,

$C^{\prime}=1+\frac{1}{s_{T}} \sum_{r_{T}=1}^{s_{T}} \frac{s_{r_{T}}^{-}}{y_{r_{T} k}}$, then the formula in model (11) can be rewritten as

$$
\theta_{k}^{P^{*}}=\frac{\frac{\alpha_{1}}{m_{P}} A+\frac{\beta_{P}}{D} E}{C}
$$

The formula in model (14) can be rewritten as

$$
\theta_{k}^{p * *}=\frac{\frac{1}{m_{P}+D}(A+E)}{C}(17) \text {. }
$$

Then we have

$$
\begin{aligned}
\theta_{k}^{P *}-\theta_{k}^{P^{*}} & \frac{\alpha_{P}}{m_{P}} A+\frac{\beta_{P}}{D} E-\frac{1}{m_{P}+D}(A+E) \\
= & \frac{\alpha_{P}\left(m_{P}+D\right)-m_{P}}{m_{P}\left(m_{P}+D\right)}+E \frac{\beta_{P}\left(m_{P}+D\right)-D}{D_{P}\left(m_{P}+D\right)} \\
= & \frac{\alpha_{P}\left(m_{P}+D\right)-m_{P}}{m_{P}+D}+\frac{\beta_{P}\left(m_{P}+D\right)-D}{m_{P}+D} \\
\leq & \frac{C}{=} \\
& 0
\end{aligned}
$$

Similarly, we have $\theta_{k}^{N^{*}} \leq \theta_{k}^{N^{* *}}, \theta_{k}^{T^{*}} \leq \theta_{k}^{T^{* *}}$.

Therefore, we have $\theta_{k}^{N^{*}} \leq \theta_{k}^{N^{* *}}, \theta_{k}^{P^{*}} \leq \theta_{k}^{P^{* *}}, \theta_{k}^{T^{*}} \leq \theta_{k}^{T^{* *}}$.

\section{Figures}




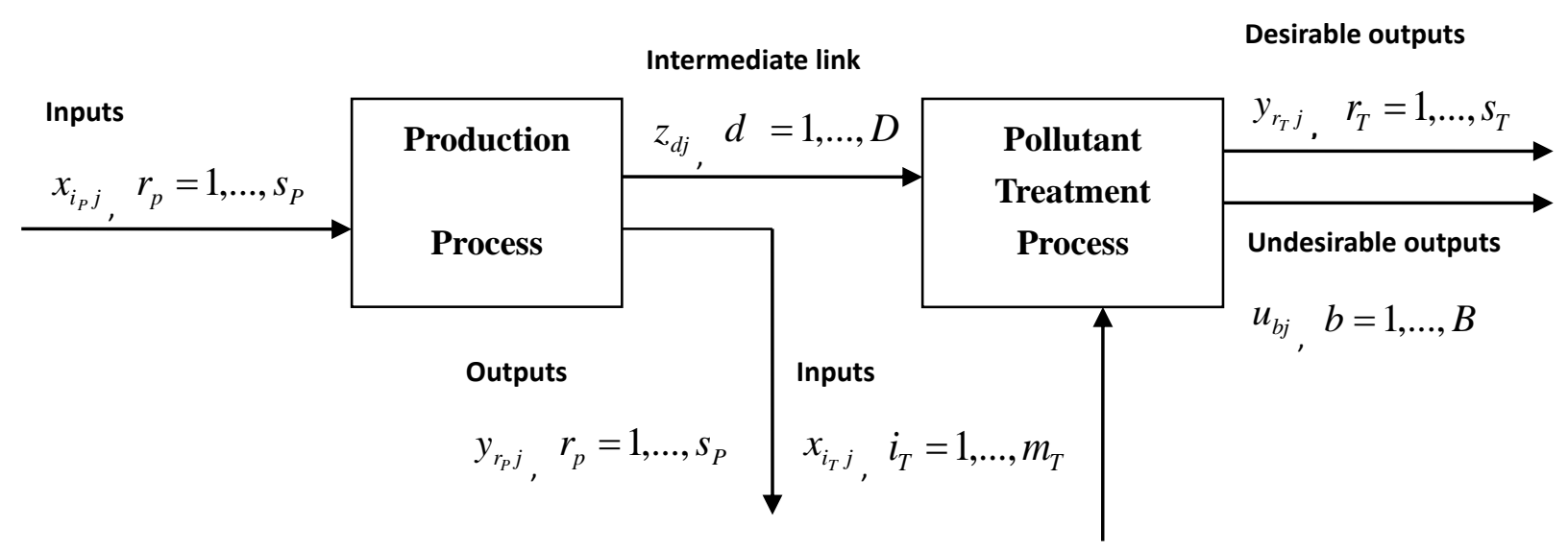

Fig.1. Flowchart of production and pollutant treatment efficiency framework

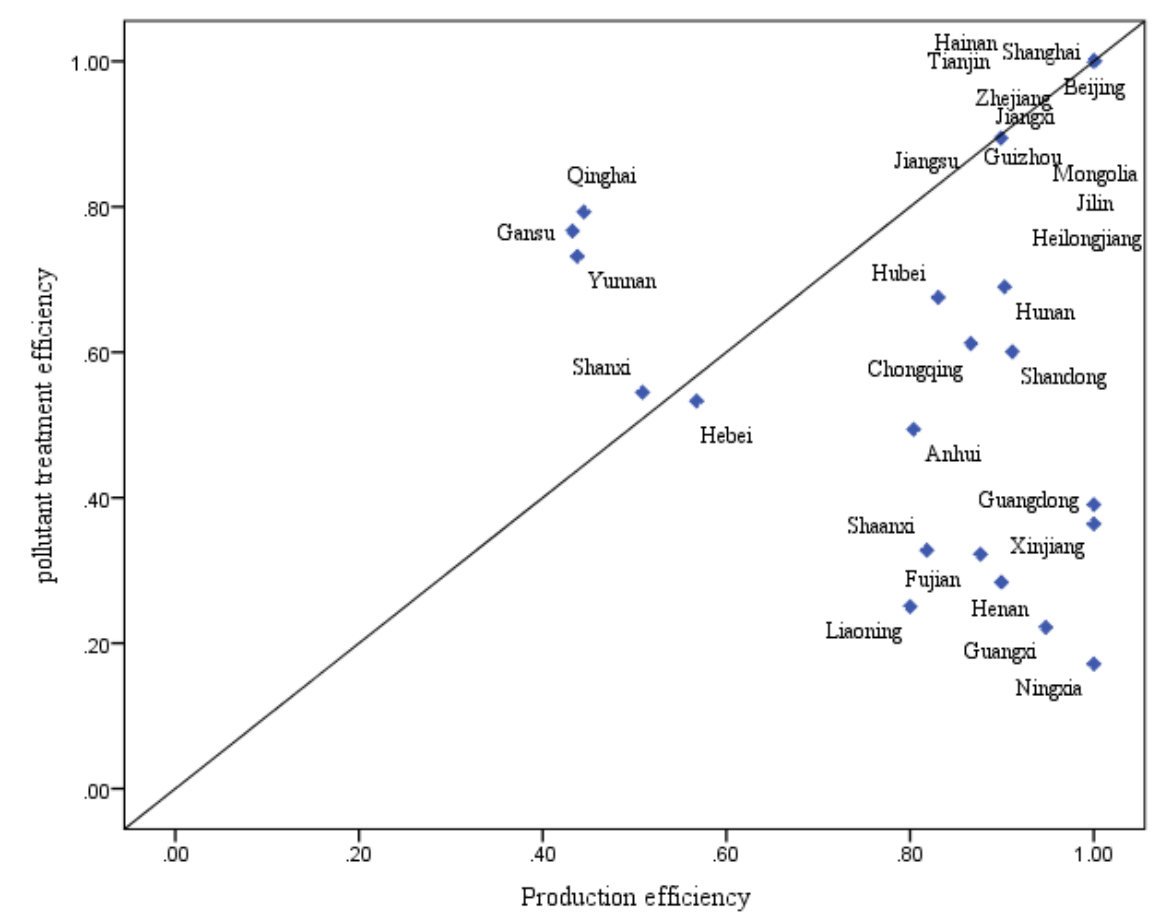

Fig.2. Plot of production efficiencies and pollutant treatment efficiencies

Tables

Table 1 Dataset and descriptive statistics

\begin{tabular}{|c|c|c|c|c|c|c|c|}
\hline & & Variables & Units & Max & Min & Mean & Std.dev. \\
\hline \multirow{3}{*}{ 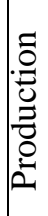 } & \multirow{3}{*}{ Inputs } & Employees & 10000 persons & 2141.91 & 53.57 & 734.31 & 636.56 \\
\hline & & Fixed assets & 1 billion Yuan & 12372.82 & 177.74 & 3810.85 & 2940.52 \\
\hline & & Electricity & (100 million $\mathrm{kW}$ & 4060.13 & 159.02 & 1399.28 & 1012.94 \\
\hline
\end{tabular}




\begin{tabular}{|c|c|c|c|c|c|c|c|}
\hline & & consumption & $\cdot \mathrm{h})$ & & & & \\
\hline & \multirow{3}{*}{$\begin{array}{c}\text { Intermed } \\
\text { iates }\end{array}$} & $\begin{array}{c}\text { COD } \\
\text { generation }\end{array}$ & 10000 tons & 261.26 & 4.24 & 61.67 & 59.22 \\
\hline & & $\begin{array}{c}\mathrm{SO}_{2} \\
\text { generation }\end{array}$ & 10000 tons & 453.54 & 11.60 & 172.28 & 106.49 \\
\hline & & $\begin{array}{l}\text { Solid waste } \\
\text { generation }\end{array}$ & 10000 tons & 31688.00 & 212.00 & 8031.00 & 6635.78 \\
\hline & $\begin{array}{l}\text { Desirabl } \\
\text { e outputs }\end{array}$ & $\begin{array}{l}\text { GDP of the } \\
\text { secondary } \\
\text { industry }\end{array}$ & 1 billion Yuan & 21462.72 & 385.21 & 6442.60 & 5475.79 \\
\hline \multirow{5}{*}{ 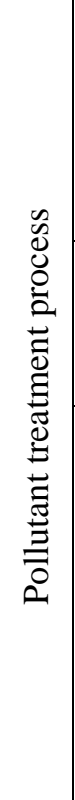 } & $\begin{array}{l}\text { Exogeno } \\
\text { us input }\end{array}$ & $\begin{array}{l}\text { Pollutant-trea } \\
\text { tment } \\
\text { investment }\end{array}$ & 1 billion Yuan & 456759.30 & $\begin{array}{c}4353.5 \\
0\end{array}$ & $\begin{array}{c}132325 . \\
61\end{array}$ & $\begin{array}{c}105065 . \\
66\end{array}$ \\
\hline & $\begin{array}{l}\text { Desirabl } \\
\text { e outputs }\end{array}$ & $\mathrm{VCU}$ & 10000 Yuan & $\begin{array}{c}2863867.0 \\
0\end{array}$ & $\begin{array}{c}31623 . \\
00\end{array}$ & $\begin{array}{c}592826 . \\
53\end{array}$ & $\begin{array}{c}650121 . \\
43\end{array}$ \\
\hline & \multirow{3}{*}{$\begin{array}{l}\text { Undesira } \\
\text { ble } \\
\text { outputs }\end{array}$} & $\begin{array}{c}\text { COD } \\
\text { emission }\end{array}$ & 10000 tons & 49.27 & 0.49 & 14.49 & 10.88 \\
\hline & & $\mathrm{SO}_{2}$ emission & 10000 tons & 138.29 & 2.82 & 62.14 & 36.13 \\
\hline & & $\begin{array}{l}\text { Solid waste } \\
\text { emission }\end{array}$ & 10000 tons & 12011.45 & 0.00 & 1925.20 & 2644.79 \\
\hline
\end{tabular}

Table 2 Results of efficiency measure for 30 regional industrial systems in China

\begin{tabular}{|c|c|c|c|c|c|c|c|}
\hline \multirow{2}{*}{ Code } & \multirow{2}{*}{ Region } & \multicolumn{2}{|c|}{$\theta_{k}^{N^{*}}$} & \multicolumn{2}{|c|}{$\theta_{k}^{P^{*}}$} & \multicolumn{2}{|c|}{$\theta_{k}^{T^{*}}$} \\
\hline & & Score & Rank & Score & Rank & Score & Rank \\
\hline \multicolumn{8}{|c|}{ Eastern area } \\
\hline $\mathrm{P} 1$ & Beijing & 1.0000 & 1 & 1.0000 & 1 & 1.0000 & 1 \\
\hline $\mathrm{P} 2$ & Tianjin & 1.0000 & 1 & 1.0000 & 1 & 1.0000 & 1 \\
\hline P3 & Hebei & 0.5505 & 19 & 0.5677 & 26 & 0.5329 & 20 \\
\hline P4 & Liaoning & 0.3969 & 29 & 0.8000 & 25 & 0.2504 & 28 \\
\hline P5 & Shanghai & 1.0000 & 1 & 1.0000 & 1 & 1.0000 & 1 \\
\hline P6 & Jiangsu & 0.8967 & 11 & 0.8990 & 18 & 0.8945 & 11 \\
\hline P7 & Zhejiang & 1.0000 & 1 & 1.0000 & 1 & 1.0000 & 1 \\
\hline
\end{tabular}




$\begin{array}{llcccccc}\text { P8 } & \text { Fujian } & 0.4805 & 26 & 0.8767 & 19 & 0.3221 & 26 \\ \text { P9 } & \text { Guangdong } & 0.5388 & 21 & 1.0000 & 1 & 0.3640 & 23 \\ \text { P10 } & \text { Hainan } & 1.0000 & 1 & 1.0000 & 1 & 1.0000 & 1 \\ \text { P11 } & \text { Shandong } & 0.7246 & 14 & 0.9115 & 15 & 0.6007 & 18\end{array}$

\section{Central area}

$\begin{array}{llcccccc}\text { P12 } & \text { Shanxi } & 0.5239 & 23 & 0.5087 & 27 & 0.5448 & 19 \\ \text { P13 } & \text { Inner } & & & & & & \\ & \text { Mongolia } & 1.0000 & 1 & 1.0000 & 1 & 1.0000 & 1 \\ \text { P14 } & \text { Jilin } & 1.0000 & 1 & 1.0000 & 1 & 1.0000 & 1 \\ \text { P15 } & \text { Heilongjiang } & 1.0000 & 1 & 1.0000 & 1 & 1.0000 & 1 \\ \text { P16 } & \text { Anhui } & 0.6153 & 16 & 0.8039 & 24 & 0.4940 & 21 \\ \text { P17 } & \text { Jiangxi } & 1.0000 & 1 & 1.0000 & 1 & 1.0000 & 1 \\ \text { P18 } & \text { Henan } & 0.4366 & 27 & 0.8994 & 17 & 0.2837 & 27 \\ \text { P19 } & \text { Hubei } & 0.7503 & 13 & 0.8307 & 21 & 0.6755 & 16 \\ \text { P20 } & \text { Hunan } & 0.7860 & 12 & 0.9029 & 16 & 0.6898 & 15 \\ \text { P21 } & \text { Guangxi } & 0.3691 & 28 & 0.9477 & 14 & 0.2218 & 29\end{array}$

Western area

$\begin{array}{lllccccc}\text { P22 } & \text { Sichuan } & 0.4907 & 24 & 0.8041 & 23 & 0.3419 & 24 \\ \text { P23 } & \text { Guizhou } & 1.0000 & 1 & 1.0000 & 1 & 1.0000 & 1 \\ \text { P24 } & \text { Yunnan } & 0.5369 & 22 & 0.4377 & 29 & 0.7318 & 14 \\ \text { P25 } & \text { Shaanxi } & 0.4858 & 25 & 0.8182 & 22 & 0.3278 & 25 \\ \text { P26 } & \text { Gansu } & 0.5421 & 20 & 0.4323 & 30 & 0.7666 & 13 \\ \text { P27 } & \text { Qinghai } & 0.5660 & 18 & 0.4448 & 28 & 0.7929 & 12 \\ \text { P28 } & \text { Ningxia } & 0.2967 & 30 & 1.0000 & 1 & 0.1715 & 30 \\ \text { P29 } & \text { Xinjiang } & 0.5747 & 17 & 1.0000 & 1 & 0.3905 & 22 \\ \text { P30 } & \text { Chongqing } & 0.7228 & 15 & 0.8661 & 20 & 0.6119 & 17\end{array}$

Averages:

\begin{tabular}{llll} 
National & 0.709 & 0.858 & 0.667 \\
Eastern & 0.781 & 0.914 & 0.724 \\
Central & 0.748 & 0.889 & 0.691 \\
Western & 0.580 & 0.756 & 0.570 \\
\hline
\end{tabular}

Table 3 Results of Spearman's correlation test

\begin{tabular}{lllllllll}
\hline & & CGI & SGI & SWGI & EI & CDI & SDI & SWDI \\
\hline OE & Coefficient & -0.312 & $-0.367 *$ & $-0.481 * *$ & -0.229 & $-0.643^{* *}$ & $-0.403^{*}$ & -0.329 \\
& Sig. & 0.093 & 0.046 & 0.007 & 0.223 & 0.000 & 0.027 & 0.0753 \\
\hline
\end{tabular}

*Correlation is significant at the 0.05 level (2-tailed).

**Correlation is significant at the 0.01 level (2-tailed).

Table 4 Sensitivity of the overall optimal efficiency to $\alpha$ and $\beta$ 


\begin{tabular}{|c|c|c|c|c|c|c|}
\hline Code & Region & $\begin{array}{l}\alpha_{1}=\alpha_{2} \\
=0.3\end{array}$ & $\begin{array}{l}\alpha_{1}=\alpha_{2} \\
=0.4\end{array}$ & $\begin{array}{l}\alpha_{1}=\alpha_{2} \\
=0.5\end{array}$ & $\begin{array}{l}\alpha_{1}=\alpha_{2} \\
=0.6\end{array}$ & $\begin{array}{l}\alpha_{1}=\alpha_{2} \\
=0.7\end{array}$ \\
\hline \multicolumn{7}{|c|}{ Eastern area } \\
\hline P1 & Beijing & $1.000(1)$ & $1.000(1)$ & $1.000(1)$ & $1.000(1)$ & $1.000(1)$ \\
\hline $\mathrm{P} 2$ & Tianjin & $1.000(1)$ & $1.000(1)$ & $1.000(1)$ & $1.000(1)$ & $1.000(1)$ \\
\hline P3 & Hebei & $0.538(19)$ & $0.544(19)$ & $0.551(19)$ & $0.556(19)$ & $0.561(20)$ \\
\hline P4 & Liaoning & $0.391(28)$ & $0.394(28)$ & $0.397(29)$ & $0.400(28)$ & $0.403(28)$ \\
\hline P5 & Shanghai & $1.000(1)$ & $1.000(1)$ & $1.000(1)$ & $1.000(1)$ & $1.000(1)$ \\
\hline P6 & Jiangsu & $0.903(11)$ & $0.900(11)$ & $0.897(11)$ & $0.893(11)$ & $0.890(11)$ \\
\hline P7 & Zhejiang & $1.000(1)$ & $1.000(1)$ & $1.000(1)$ & $1.000(1)$ & $1.000(1)$ \\
\hline P8 & Fujian & $0.481(25)$ & $0.481(25)$ & $0.480(26)$ & $0.480(26)$ & $0.480(26)$ \\
\hline P9 & Guangdong & $0.537(20)$ & $0.538(20)$ & $0.539(21)$ & $0.540(22)$ & $0.540(22)$ \\
\hline P10 & Hainan & $1.000(1)$ & $1.000(1)$ & $1.000(1)$ & $1.000(1)$ & $1.000(1)$ \\
\hline $\mathrm{P} 11$ & Shandong & $0.719(14)$ & $0.722(14)$ & $0.725(14)$ & $0.727(15)$ & $0.729(15)$ \\
\hline \multicolumn{7}{|c|}{ Central area } \\
\hline P12 & Shanxi & $0.509(23)$ & $0.516(23)$ & $0.524(23)$ & $0.531(23)$ & $0.538(23)$ \\
\hline P13 & Inner Mongolia & $1.000(1)$ & $1.000(1)$ & $1.000(1)$ & $1.000(1)$ & $1.000(1)$ \\
\hline P14 & Jilin & $1.000(1)$ & $1.000(1)$ & $1.000(1)$ & $1.000(1)$ & $1.000(1)$ \\
\hline P15 & Heilongjiang & $1.000(1)$ & $1.000(1)$ & $1.000(1)$ & $1.000(1)$ & $1.000(1)$ \\
\hline P16 & Anhui & $0.611(16)$ & $0.613(16)$ & $0.615(16)$ & $0.617(16)$ & $0.616(16)$ \\
\hline P17 & Jiangxi & $1.000(1)$ & $1.000(1)$ & $1.000(1)$ & $1.000(1)$ & $1.000(1)$ \\
\hline P18 & Henan & $0.432(27)$ & $0.435(27)$ & $0.437(27)$ & $0.438(27)$ & $0.439(27)$ \\
\hline P19 & Hubei & $0.736(13)$ & $0.743(13)$ & $0.750(13)$ & $0.755(13)$ & $0.759(13)$ \\
\hline $\mathrm{P} 20$ & Hunan & $0.771(12)$ & $0.778(12)$ & $0.786(12)$ & $0.793(12)$ & $0.796(12)$ \\
\hline \multicolumn{7}{|c|}{ Western area } \\
\hline $\mathrm{P} 21$ & Guangxi & $0.362(29)$ & $0.366(29)$ & $0.369(28)$ & $0.373(29)$ & $0.376(29)$ \\
\hline $\mathrm{P} 22$ & Sichuan & $0.481(24)$ & $0.486(24)$ & $0.491(24)$ & $0.494(24)$ & $0.498(24)$ \\
\hline $\mathrm{P} 23$ & Guizhou & $1.000(1)$ & $1.000(1)$ & $1.000(1)$ & $1.000(1)$ & $1.000(1)$ \\
\hline P24 & Yunnan & $0.528(21)$ & $0.532(22)$ & $0.537(22)$ & $0.541(21)$ & $0.546(21)$ \\
\hline $\mathrm{P} 25$ & Shaanxi & $0.472(26)$ & $0.479(26)$ & $0.486(25)$ & $0.493(25)$ & $0.498(25)$ \\
\hline P26 & Gansu & $0.523(22)$ & $0.532(21)$ & $0.542(20)$ & $0.552(20)$ & $0.562(19)$ \\
\hline P27 & Qinghai & $0.565(17)$ & $0.566(18)$ & $0.566(18)$ & $0.566(18)$ & $0.567(18)$ \\
\hline $\mathrm{P} 28$ & Ningxia & $0.294(30)$ & $0.296(30)$ & $0.297(30)$ & $0.298(30)$ & $0.298(30)$ \\
\hline P29 & Xinjiang & $0.563(18)$ & $0.569(17)$ & $0.575(17)$ & $0.580(17)$ & $0.583(17)$ \\
\hline $\mathrm{P} 30$ & Chongqing & $0.705(15)$ & $0.714(15)$ & $0.723(15)$ & $0.732(14)$ & $0.738(14)$ \\
\hline
\end{tabular}

Table 5 A three-year window analysis of the overall efficiency of Hunan (P20)

\begin{tabular}{lccccccc}
\hline Windows & 2004 & 2005 & 2006 & 2007 & 2008 & 2009 & 2010 \\
\hline Window 1 & 0.4086 & 0.4379 & 0.5427 & & & & \\
Window 2 & & 0.3568 & 0.4528 & 0.5688 & & & \\
Window 3 & & & 0.4432 & 0.5403 & 0.6521 & & \\
Window 4 & & & & 0.5408 & 0.6555 & 0.7139 & \\
Window 5 & & & & & 0.6256 & 0.7002 & 0.7581
\end{tabular}




\begin{tabular}{llllllll} 
Average & 0.4086 & 0.3973 & 0.4796 & 0.5500 & 0.6444 & 0.7070 & 0.7581 \\
\hline
\end{tabular}

Table 6 Overall efficiency scores of 30 regional industrial systems in China

\begin{tabular}{|c|c|c|c|c|c|c|c|c|c|}
\hline & & 2004 & 2005 & 2006 & 2007 & 2008 & 2009 & 2010 & Average \\
\hline \multicolumn{10}{|l|}{ Eastern area } \\
\hline $\mathrm{P} 1$ & Beijing & 0.9047 & 1.0000 & 0.9585 & 0.8773 & 1.0000 & 0.9882 & 1.0000 & 0.9612 \\
\hline $\mathrm{P} 2$ & Tianjin & 0.4852 & 0.5036 & 0.9251 & 0.7649 & 0.7716 & 1.0000 & 1.0000 & 0.7786 \\
\hline P3 & Hebei & 0.3921 & 0.3915 & 0.4383 & 0.4982 & 0.7713 & 0.4970 & 0.5259 & 0.5020 \\
\hline P4 & Liaoning & 0.4177 & 0.3286 & 0.3640 & 0.4572 & 0.4778 & 0.4989 & 0.3909 & 0.4193 \\
\hline P5 & Shanghai & 0.8952 & 0.8221 & 0.7283 & 1.0000 & 0.9808 & 0.8624 & 1.0000 & 0.8984 \\
\hline P6 & Jiangsu & 0.5863 & 0.7006 & 0.8158 & 0.8545 & 0.8921 & 0.9056 & 0.8907 & 0.8065 \\
\hline P7 & Zhejiang & 0.7554 & 0.5422 & 0.8678 & 0.9624 & 0.9761 & 0.9433 & 1.0000 & 0.8639 \\
\hline P8 & Fujian & 0.3847 & 0.3386 & 0.3732 & 0.3251 & 0.3784 & 0.6089 & 0.4647 & 0.4105 \\
\hline P9 & Guangdong & 0.4889 & 0.5470 & 1.0000 & 0.8647 & 0.5411 & 0.7342 & 0.5324 & 0.6726 \\
\hline P10 & Hainan & 0.4392 & 0.7344 & 0.4311 & 1.0000 & 0.6582 & 0.4324 & 1.0000 & 0.6708 \\
\hline \multirow[t]{2}{*}{$\mathrm{P} 11$} & Shandong & 0.5035 & 0.5954 & 0.6065 & 0.7084 & 0.7149 & 0.7035 & 0.6750 & 0.6439 \\
\hline & Average & 0.5685 & 0.5913 & 0.6826 & 0.7557 & 0.7420 & 0.7431 & 0.7709 & 0.6934 \\
\hline \multicolumn{10}{|l|}{ Central area } \\
\hline P12 & Shanxi & 0.3927 & 0.4266 & 0.3805 & 0.4708 & 0.4967 & 0.4303 & 0.5063 & 0.4434 \\
\hline P13 & $\begin{array}{l}\text { Inner } \\
\text { Mongolia }\end{array}$ & 0.3230 & 0.4065 & 0.1931 & 0.3522 & 0.3526 & 0.3712 & 1.0000 & 0.4284 \\
\hline P14 & Jilin & 0.5603 & 0.4638 & 0.5912 & 0.5803 & 0.6952 & 0.6952 & 0.8643 & 0.6358 \\
\hline P15 & Heilongjiang & 1.0000 & 0.6380 & 0.7201 & 0.6238 & 0.8300 & 0.5024 & 0.6870 & 0.7145 \\
\hline P16 & Anhui & 0.4318 & 0.4604 & 0.4451 & 0.4992 & 0.5589 & 0.5333 & 0.6015 & 0.5043 \\
\hline P17 & Jiangxi & 0.5151 & 0.5373 & 0.6044 & 0.6149 & 0.6429 & 0.8349 & 1.0000 & 0.6785 \\
\hline P18 & Henan & 0.3464 & 0.3110 & 0.3415 & 0.3360 & 0.4231 & 0.4146 & 0.4259 & 0.3712 \\
\hline P19 & Hubei & 0.7628 & 0.6394 & 0.6663 & 0.6761 & 0.6570 & 0.6717 & 0.7219 & 0.6850 \\
\hline P20 & Hunan & 0.4086 & 0.3973 & 0.4796 & 0.5500 & 0.6444 & 0.7070 & 0.7581 & 0.5636 \\
\hline \multirow[t]{2}{*}{$\mathrm{P} 21$} & Guangxi & 0.5222 & 0.3558 & 0.3956 & 0.4143 & 0.3621 & 0.3279 & 0.3548 & 0.3904 \\
\hline & Average & 0.5263 & 0.4636 & 0.4817 & 0.5118 & 0.5663 & 0.5489 & 0.6920 & 0.5415 \\
\hline \multicolumn{10}{|l|}{ Western area } \\
\hline P22 & Sichuan & 0.3296 & 0.4729 & 0.4447 & 0.4124 & 0.4422 & 0.5204 & 0.4751 & 0.4425 \\
\hline $\mathrm{P} 23$ & Guizhou & 0.4741 & 1.0000 & 0.6228 & 0.7809 & 1.0000 & 0.4752 & 0.5054 & 0.6941 \\
\hline $\mathrm{P} 24$ & Yunnan & 0.5364 & 0.7538 & 0.4813 & 0.5295 & 0.5524 & 0.4945 & 0.5208 & 0.5527 \\
\hline P25 & Shaanxi & 0.1853 & 0.1580 & 0.2557 & 0.3150 & 0.2799 & 0.3886 & 0.4556 & 0.2912 \\
\hline P26 & Gansu & 0.4209 & 0.4485 & 0.4364 & 0.5054 & 0.4993 & 1.0000 & 0.5157 & 0.5466 \\
\hline P27 & Qinghai & 1.0000 & 0.3263 & 0.4188 & 0.8352 & 0.4731 & 0.4887 & 0.5342 & 0.5823 \\
\hline P28 & Ningxia & 0.1895 & 0.1859 & 0.1874 & 0.1814 & 0.2208 & 0.2328 & 0.2794 & 0.2110 \\
\hline P29 & Xinjiang & 0.4021 & 0.4062 & 0.3172 & 0.3596 & 0.3466 & 0.4169 & 0.5673 & 0.4023 \\
\hline \multirow[t]{2}{*}{ P30 } & Chongqing & 0.4451 & 0.3410 & 0.4457 & 0.4733 & 0.5433 & 0.6664 & 0.6973 & 0.5160 \\
\hline & Average & 0.4426 & 0.4547 & 0.4011 & 0.4881 & 0.4842 & 0.5204 & 0.5056 & 0.4710 \\
\hline \multicolumn{2}{|c|}{ National Average } & 0.5166 & 0.5078 & 0.5312 & 0.5941 & 0.6061 & 0.6116 & 0.6650 & 0.5761 \\
\hline
\end{tabular}

